\title{
Effects of graphene oxide on dispersion stability of Titanium dioxide nanoparticles
}

\author{
Pingping Song ${ }^{1}$, Yongpeng Wei, and Xuesong Cao *a \\ ${ }^{1}$ College of Environmental Science and Engineering, Ocean University of China, Qingdao 266100, \\ China \\ ${ }^{* a}$ caoxuesong521123@126.com
}

Keywords: graphene oxide, titanium dioxide nanoparticles, dispersion stability, heteroaggregation.

\begin{abstract}
In this work, we investigated the effects of GO on dispersion stability of the two types of $\mathrm{TiO}_{2}$ NPs under different $\mathrm{pHs}$. At $\mathrm{pH}$ 4, heteroaggregation may occur between $\mathrm{GO}$ and the two types of $\mathrm{TiO}_{2}$ NPs $\left(\mathrm{TiO}_{2}\right.$ Nanotube and $\mathrm{TiO}_{2}$ Nanowire), enhancing the sedimentation of $\mathrm{TiO}_{2} \mathrm{NPs}$. However, at pH 7 and 10, GO enhanced the suspension of the two types of $\mathrm{TiO}_{2} \mathrm{NPs}_{\text {. Electrostatic }}$ interaction could be a major mechanism for $\mathrm{TiO}_{2}$ NPs-GO interaction.
\end{abstract}

\section{Introduction}

Titanium dioxide nanoparticles $\left(\mathrm{TiO}_{2} \mathrm{NPs}\right)$ are widely used in commercial applications such as photocatalysts, ceramic membranes, and cosmetic pigment additives ${ }^{[1]}$. Graphene Oxide (GO) is a promising material for wide applications such as dispersing agent, adsorbent and catalytic material ${ }^{[2,}$ ${ }^{3]}$. With the rapid increases in production and application, $\mathrm{TiO}_{2} \mathrm{NPs}$ and GO will be released into aquatic environment. Upon exposure, they will exhibit adverse impacts on organisms. Hund-Rinke and Simon (2006) reported that $\mathrm{TiO}_{2}$ NPs can inhibit the growth of algae and the immobilization of daphnia ${ }^{[4]}$. Once $\mathrm{TiO}_{2}$ NPs are released into the aquatic environment, their fate and transport will affect their phototoxicity and ecotoxicity ${ }^{[5,6]}$. Tong et al. revealed that the presence of both nano- $\mathrm{ZnO}$ and dissolved zinc eliminated the damaging effect of nano- $\mathrm{TiO}_{2}$ on bacterial cell membranes, which was explained by a reduced extent of bacteria/nano- $\mathrm{TiO}_{2}$ contact ${ }^{[7]}$. $\mathrm{GO}$ can disperse in water to form stable colloidal suspensions ${ }^{[8]}$, and GO may interact with $\mathrm{TiO}_{2} \mathrm{NPs}$, altering the potential exposure pathways and biovailability of $\mathrm{TiO}_{2} \mathrm{NPs}$. Therefore, it is important to investigate the effects of GO on the fate and transport of $\mathrm{TiO}_{2} \mathrm{NPs}$.

The main objective of this study was to investigate the effects of GO on dispersion stability of $\mathrm{TiO}_{2}$ NPs under different pHs.

\section{Materials and Method}

Suspension and Sedimentation Experiment. The two types of $\mathrm{TiO}_{2} \mathrm{NPs}\left(\mathrm{TiO}_{2} \mathrm{Nanotube}\right.$ and $\mathrm{TiO}_{2}$ Nanowire) were purchased from Nanjing XFNANO (China). GO was produced by the modified Hummers method ${ }^{[9]}$. $\mathrm{TiO}_{2}$ NPs stock solution $(200 \mathrm{mg} / \mathrm{L})$ was prepared by sonicating for $10 \mathrm{~min}$ (20 $\mathrm{kHz}$, FB 120, Fisher Scientific, USA). GO stock solution (250 mg/L) was prepared by sonicating for $60 \mathrm{~min}$ (20 kHz, FB 120, Fisher Scientific, USA).The $\mathrm{pH}$ of the suspension was adjusted by adding negligible amounts of $\mathrm{NaOH}$ or $\mathrm{HCl} .10 \mathrm{~mL} \mathrm{TiO}_{2} \mathrm{NPs}$ stock solution and $10 \mathrm{~mL}$ DI water were mixed to get $100 \mathrm{mg} / \mathrm{L} \mathrm{TiO}_{2}$ NPs. $10 \mathrm{~mL} \mathrm{TiO}_{2}$ NPs stock solution, $6 \mathrm{~mL}$ DI water , and $4 \mathrm{~mL}$ GO stock solution were mixed to get the mixture of $100 \mathrm{mg} / \mathrm{L} \mathrm{TiO}{ }_{2} \mathrm{NPs}$ and $50 \mathrm{mg} / \mathrm{L} \mathrm{GO}$. The mixtures were shaken (150 rpm in dark) at $25^{\circ} \mathrm{C}$ for $36 \mathrm{~h}$ and then settled for $5 \mathrm{~h}$. The dispersion stability of $\mathrm{TiO}_{2}$ NPs was measured by UV-Vis spectrophotometer (SHIMADZU 2550, Japan). Briefly, the supernatants $(3 \mathrm{~mL})$ were carefully moved to quartz cuvette and examined at $800 \mathrm{~nm}$ to get the absorbance $A$. Before sedimentation, the suspensions ( $3 \mathrm{~mL}$ ) were also examined at $800 \mathrm{~nm}$ to get the absorbance $A_{0}$. The absorbance of GO at $800 \mathrm{~nm}$ could be negative (data were not shown), so the sedimentation rate of $\mathrm{TiO}_{2} \mathrm{NPs}$ is calculated by the equation as follows:

Sedimentation Rate $(\%)=\left(\mathrm{A}_{0}-\mathrm{A}\right) / \mathrm{A}_{0} * 100 \%$ 
Statistical Analysis. Data was analyzed using a one-way analysis of variance (ANOVA) and compared with LSD test. All data included three replicates and standard error was statistically analyzed $(\mathrm{p}<0.05)$.

\section{Results and discussion}

Characterization of $\mathrm{TiO}_{2}$ NPs and GO. Characterization of $\mathrm{TiO}_{2} \mathrm{NPs}$ and $\mathrm{GO}$ was analyzed by transmission electron microscopy (TEM, H-7650, Hitachi, Japan). The TEM images showed that the length of $\mathrm{TiO}_{2}$ Nanotube was 100-200 nm and the width was $\sim 10 \mathrm{~nm}$ (Fig. 1A). The length of $\mathrm{TiO}_{2}$ Nanowire was 50-300 nm and the width was $10 \mathrm{~nm}$ (Fig. 1B). The lateral size of GO sheets was at the micrometer level, and the GO sheets were flexible and could be folded (Fig. 1C).
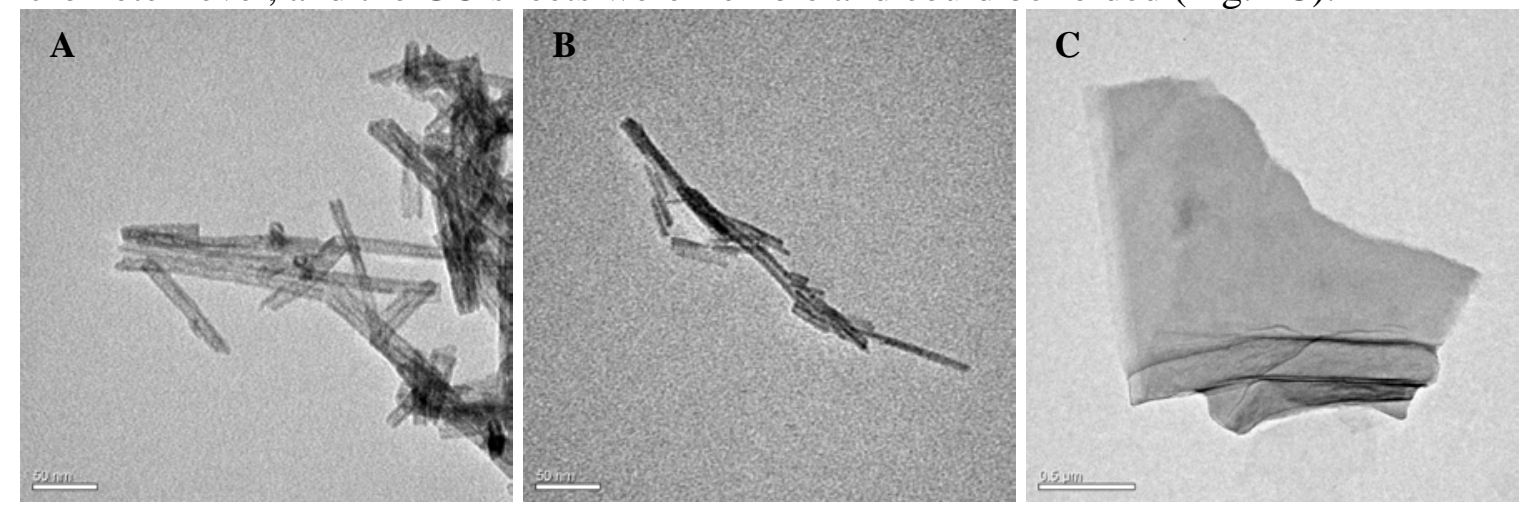

Fig. 1 TEM images of $\mathrm{TiO}_{2}$ NPs and GO. (A) $\mathrm{TiO}_{2}$ Nanotube; (B) $\mathrm{TiO}_{2}$ Nanowire; (C) GO.

The zeta potentials of $\mathrm{TiO}_{2}$ NPs and GO were measured by Zetasizer (Nano ZS90, Malvern, UK). The zeta potentials of $\mathrm{TiO}_{2}$ NPs and GO under different $\mathrm{pHs}$ were showed in Table 1 . At $\mathrm{pH} 4$, the zeta potential of $\mathrm{TiO}_{2}$ Nanotube and $\mathrm{TiO}_{2}$ Nanowire was $5.52 \mathrm{mV}$ and $2.30 \mathrm{mV}$, respectively. At pH 7, the zeta potential of $\mathrm{TiO}_{2}$ Nanotube and $\mathrm{TiO}_{2}$ Nanowire was $-32.5 \mathrm{mV}$ and $-47.4 \mathrm{mV}$, respectively. At $\mathrm{pH}$ 10, the zeta potential of $\mathrm{TiO}_{2}$ Nanotube and $\mathrm{TiO}_{2}$ Nanowire was $-41.5 \mathrm{mV}$ and $-48.1 \mathrm{mV}$, respectively. However, GO was highly negatively charged at 4, 7, and 10.

Table 1 The zeta potentials of $\mathrm{TiO}_{2}$ NPs and GO under different pHs

\begin{tabular}{cccc}
\hline $\mathrm{pH}$ & $\mathrm{TiO}_{2}$ Nanotube $(\mathrm{mV})$ & $\mathrm{TiO}_{2}$ Nanowire $(\mathrm{mV})$ & $\mathrm{GO}(\mathrm{mV})$ \\
\hline 4 & $5.52 \pm 0.57$ & $2.30 \pm 0.3$ & $-40.5 \pm 0.9$ \\
7 & $-32.5 \pm 1.5$ & $-47.4 \pm 4.3$ & $-40.2 \pm 2.0$ \\
10 & $-41.5 \pm 2.0$ & $-48.1 \pm 2.4$ & $-42.1 \pm 1.8$
\end{tabular}

Effects of GO on Dispersion Stability of $\mathrm{TiO}_{2}$ NPs. Fig. 2 showed the effects of GO on dispersion stability of $\mathrm{TiO}_{2}$ NPs under different pHs. At $\mathrm{pH} \mathrm{4}$, the presence of GO enhanced the sedimentation rate of the two types of $\mathrm{TiO}_{2} \mathrm{NPs}$ in comparison with that in the absence of GO. It showed that GO enhanced the sedimentation of the two types of $\mathrm{TiO}_{2} \mathrm{NPs}$ at $\mathrm{pH} 4$. For the two types of $\mathrm{TiO}_{2} \mathrm{NPs}$, GO enhanced the sedimentation rate of $\mathrm{TiO}_{2}$ Nanotube more significantly than that of $\mathrm{TiO}_{2}$ Nanowire. However, at pH 7 and 10, the presence of GO reduced the sedimentation rate of the two types of $\mathrm{TiO}_{2}$ NPs in comparison with that in the absence of GO. It showed that GO enhanced the suspension of the two types of $\mathrm{TiO}_{2} \mathrm{NPs}$ at $\mathrm{pH} 7$ and 10. For the two types of $\mathrm{TiO}_{2} \mathrm{NPs}$, GO reduced the sedimentation rate of $\mathrm{TiO}_{2}$ Nanowire more significantly than that of $\mathrm{TiO}_{2}$ Nanotube. In Table 1, $\mathrm{TiO}_{2}$ NPs and GO were opposite charged at $\mathrm{pH} 4$, heteroaggregation may occur between $\mathrm{GO}$ and the two types of $\mathrm{TiO}_{2} \mathrm{NPs}$. However, $\mathrm{TiO}_{2} \mathrm{NPs}$ and GO were both highly negatively charged at $\mathrm{pH} 7$ and 10. We assumed that electrostatic interaction could be a major mechanism for $\mathrm{TiO}_{2} \mathrm{NPs}_{-\mathrm{GO}}$ interaction. The results in our study were consistent of the study on the interaction between GO and goethite ${ }^{[10]}$. 

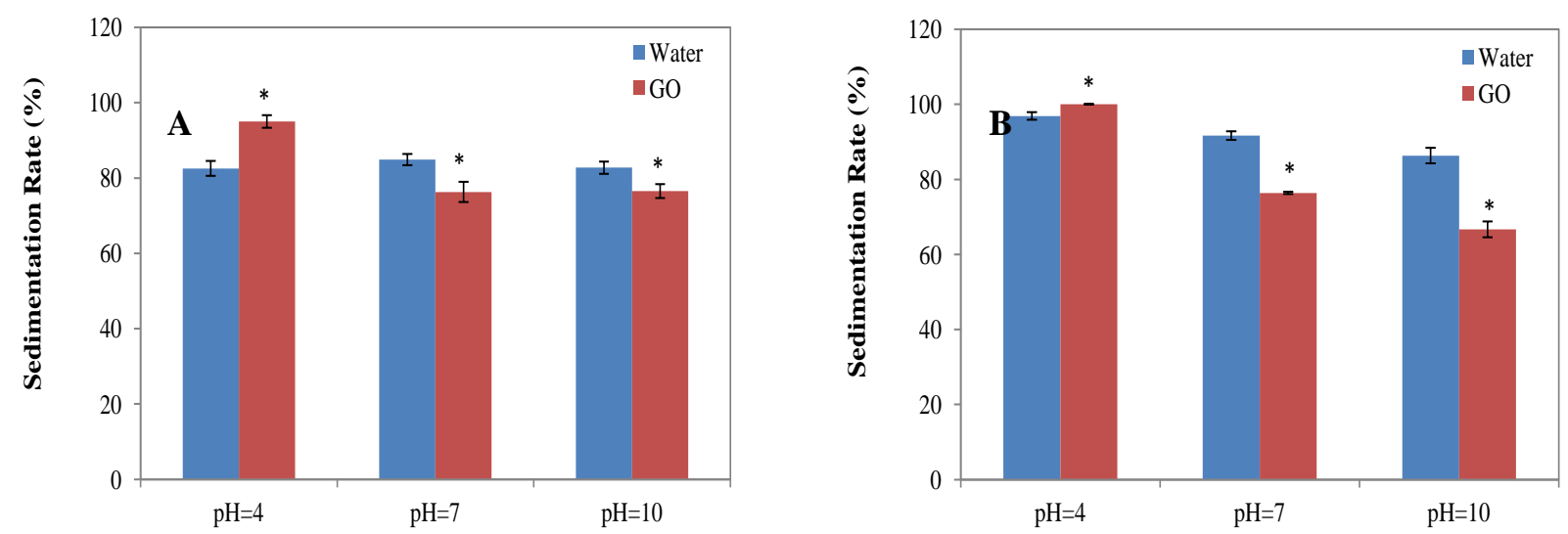

Fig. 2 Effects of GO on dispersion stability of $\mathrm{TiO}_{2}$ NPs under different pHs. (A) $\mathrm{TiO}_{2}$ Nanotube; (B) $\mathrm{TiO}_{2}$ Nanowire. The blue column indicates $100 \mathrm{mg} / \mathrm{L} \mathrm{TiO}{ }_{2} \mathrm{NPs}$ in DI water, and the red column indicates $100 \mathrm{mg} / \mathrm{L} \mathrm{TiO}_{2}$ NPs in $50 \mathrm{mg} / \mathrm{L}$ GO. Error bars indicate one standard deviation of at least three measurements. “*” indicates significant difference of sedimentation rate in the presence of GO in comparison with that in the absence of GO $(p<0.05)$.

\section{Summary}

At $\mathrm{pH}$ 4, heteroaggregation may occur between $\mathrm{GO}$ and the two types of $\mathrm{TiO}_{2} \mathrm{NPs}$, enhancing the sedimentation of the two types of $\mathrm{TiO}_{2} \mathrm{NPs}$. For the two types of $\mathrm{TiO}_{2} \mathrm{NPs}$, GO enhanced the sedimentation rate of $\mathrm{TiO}_{2}$ Nanotube more significantly than that of $\mathrm{TiO}_{2}$ Nanowire. At pH 7 and 10, GO enhanced the suspension of the two types of $\mathrm{TiO}_{2}$ NPs. For the two types of $\mathrm{TiO}_{2} \mathrm{NPs}$, GO reduced the sedimentation rate of $\mathrm{TiO}_{2}$ Nanowire more significantly than that of $\mathrm{TiO}_{2}$ Nanotube. Electrostatic interaction could be a major mechanism for $\mathrm{TiO}_{2} \mathrm{NPs}-\mathrm{GO}$ interaction.

\section{References}

[1] Zhang C, Li Y, Wang D, et al. Ag@ helical chiral $\mathrm{TiO}_{2}$ nanofibers for visible light photocatalytic degradation of 17 $\alpha$-ethinylestradiol. Environmental Science and Pollution Research, 2015, 22(14): 10444-10451.

[2] Zurutuza, A.; Marinelli, C. Challenges and opportunities in graphene commercialization. Nat. nanotechnol. 2014, 9(10), 730-734.

[3] Novoselov, K. S.; Fal, V. I.; Colombo, L.; Gellert, P. R.; Schwab, M. G.; Kim, K. A roadmap for graphene. Nature 2012, 490(7419), 192-200.

[4] Hund-Rinke K, Simon M. Ecotoxic effect of photocatalytic active nanoparticles $\left(\mathrm{TiO}_{2}\right)$ on algae and daphnids (8 pp). Environmental Science and Pollution Research, 2006, 13(4): 225-232.

[5] Li S, Pan X, Wallis L K, et al. Comparison of $\mathrm{TiO}_{2}$ nanoparticle and graphene- $\mathrm{TiO}_{2}$ nanoparticle composite phototoxicity to Daphnia magna and Oryzias latipes. Chemosphere, 2014, 112: 62-69.

[6] Salieri B, Righi S, Pasteris A, et al. Freshwater ecotoxicity characterisation factor for metal oxide nanoparticles: A case study on titanium dioxide nanoparticle. Science of The Total Environment, 2015, 505: 494-502.

[7] Tong $\mathrm{T}$, Wilke $\mathrm{C} \mathrm{M}$, Wu J, et al. Combined toxicity of nano- $\mathrm{ZnO}$ and nano- $\mathrm{TiO}_{2}$ : from single-to multinanomaterial systems. Environmental science \& technology, 2015, 49(13): 8113-8123.

[8] Stankovich S, Piner R D, Nguyen S B T, et al. Synthesis and exfoliation of isocyanate-treated graphene oxide nanoplatelets. Carbon, 2006, 44(15): 3342-3347. 
[9] Kovtyukhova, N. I.; Ollivier, P. J.; Martin, B. R.; Mallouk, T. E.;Chizhik, S. A.; Buzaneva, E. V.; Gorchinskiy, A. D. Layer-by-layerassembly of ultrathin composite films from micron-sized graphite oxide sheets and polycations. Chem. Mater. 1999, 11 (3), 771-778.

[10] Zhao J, Liu F, Wang Z, et al. Heteroaggregation of graphene oxide with minerals in aqueous phase. Environmental science \& technology, 2015, 49(5): 2849-2857. 